\title{
Nutritional status and food-related quality of life in free-living older adults
}

\author{
N. Omar, M. Gibbs and K. Hart \\ Faculty of Health and Medical Sciences, University of Surrey, Guildford GU2 7XH, UK
}

\begin{abstract}
Malnutrition in older people is related to increased mortality, risk of fracture, infections and specific nutrient deficiencies, leading to a variety of health-related conditions that can greatly affect the quality of life ${ }^{(1)}$. Although institutionalised older adults have been shown to be at high risk of malnutrition ${ }^{(2)}$, previous research has shown that, even among independent older people, $3 \%$ of men and $6 \%$ of women are underweight ${ }^{(3)}$. With the proportion of the UK population that is over 75 years of age likely to double in the next 40 years ${ }^{(4)}$, and $10 \%$ of the UK free-living older population classified as underweight ${ }^{(5)}$, screening for nutritional status should be undertaken routinely in elderly patients living at home to determine their risk of malnutrition ${ }^{(6)}$.

The aim of this study was to determine the nutritional status, dietary variety and factors affecting satisfaction with food-related quality of life in older people living in their own homes.

Twenty free-living people over 75 years old were recruited from day centres and local advertisements to participate in this study. Data were collected at 3 time points, once at the day centre or the subjects home to complete the Mini Nutritional Assessment (MNA), the Satisfaction with Food-related Life (SWFL) questionnaire ${ }^{(7)}$, and one $24 \mathrm{~h}$ diet recall, plus 2 further $24 \mathrm{~h}$ recalls, undertaken by telephone. The data were analysed by Dietplan 6 and SPSS (version 16).

The subjects comprised 14 females and 6 males with a mean age of 83.8 (SD 4.7) years and 79.0 (SD 1.7) years, respectively. There was a significant difference in age between males and females $(t=0.033, P=0.004)$. BMI for females were between 20.0 and $38.0 \mathrm{~kg} / \mathrm{m}^{2}$ and for males from 22.4 to $35.0 \mathrm{~kg} / \mathrm{m}^{2}$. There were no significant differences in weight, BMI or mid-arm circumference (MAC) between males and females $(P>0.05)$. The majority $(65 \%)$ of subjects were normal weight and $35 \%$ were overweight. None of the subjects were classified as underweight. However, the MNA results indicated that $30 \%$ were at risk of malnutrition (MNA indicator score 17 to 23.5 ). SWFL results showed that the majority of subjects strongly agreed with each item, indicating that they were very satisfied with their foodrelated life. Only responses to item 1 (food and meals are positive elements in my life) were significantly different between males and females $(t=0.019, P=0.028)$, with men being more satisfied than women. Unexpectedly, there were no significant differences in SWFL scores between 'at risk' and 'normal' subjects, which may suggest that older people's relationship with food is relatively robust and not easily influenced by nutritional status.

This study has identified that a significant proportion, 30\%, of an older free-living population is classified as being 'at risk' of malnutrition, and we suggest that this may be an underestimation of the true proportion since our recruitment strategy may have inadvertently been biased towards healthier free-living older adults. It would be of value to extend this work to older people in care and to seek access to the more isolated free-living older adults.
\end{abstract}

1. Lehmann (1991) Nutrition in old age: an update and questions for future research. Part 1. Rev Clin Gerontol 1, 135-145.

2. Russell C \& Elia M (2008). Nutrition Screening Survey in the UK 2007. A Report by BAPEN. Redditch: BAPEN.

3. Finch S, Doyle W, Lowe C et al. (1998) National Diet and Nutrition Survey: People aged 65 Years and Over: Volume 1: Report of the Diet and Nutrition Survey. London: The Stationary Office.

4. Thomas (1998) Nutrition and the Elderly. Nursing Times - Nutrition in Practice 10.

5. Pullinger (1999) Office for National Statistics. Social Trends 29.

6. Holmes (2000) Nutritional Screening and Older Adults. Nursing Standard 15(2), 42-44.

7. Grunert KG, Dean M, Raats MM et al. (2007) Food in later in life team. A measure of satisfaction with food-related life. Appetite 49, 486-493. 